\title{
UTILIZAÇÃO DO ENSINO BASEADO NA WEB NA FORMAÇÃO DOCENTE
}

\author{
Ketiuce Ferreira Silva - UAB/UFU - ketiuce@yahoo.com.br
}

\begin{abstract}
Resumo: Este artigo tem por objetivo fornecer subsídios, teóricos e práticos, que contribuam com o ensino apoiado pelas tecnologias de informação e comunicação (TICs), mais especificamente da WebQuest (WQ). Para tanto, realizou-se uma pesquisa teórica sobre o tema, coletou-se um relato de experiência docente em uma proposta de formação destinada a professores e analisou-se a vivência relatada a partir do referencial teórico apresentado. A internet, como parte integrante das tecnologias digitais, possui significativo acervo de informação passível de ser transformado em conhecimento. Atualmente, não se fala em trabalhar para a educação ignorando as tecnologias de informação e comunicação. Dessa forma, educadores precisam ter conhecimentos, habilidades e atitudes que os tornem capazes de direcionar e explorar o potencial dessas tecnologias de maneira positiva e eficiente.
\end{abstract}

Palavras-chave: educação; ensino baseado na web; formação docente; WebQuest.

\section{Learning using the web in teacher formation}

\begin{abstract}
This article aims to provide support, theoretical and practical, to contribute with the job of education, using information and communication technologies (ICTs), specifically the WebQuest (WQ). Thus, with a theoretical research on the subject, it was collected teaching experience in a teachers' training and it was considered an experience reported from the theoretical framework presented. The Internet, as a digital technology, has significant informations that can be transformed into knowledge. Currently, it is not possible to work without information and communication technologies. Thus, teachers must be able to explore the potential of these technologies in a positive and efficient way.
\end{abstract}

Keywords: education; education based on the web; teacher formation; WebQuest.

\section{Introdução}

A intensa presença das Tecnologias de Informação e Comunicação (TICs), nos mais diferentes contextos, é uma realidade característica da chamada "Sociedade do Conhecimento". Assim como o computador, programas de diferentes finalidades, e outros recursos presentes no contexto digital, a internet também se coloca como um aspecto que exerce forte influência nessa atual conjuntura. As palavras de Masetto (2000) explicam o que são esses recursos:

Por novas tecnologias em educação, estamos entendendo o uso da informática, do computador, da internet, do CD-ROM, da hipermídia, da multimídia, de ferramentas para educação a distância - como chats, grupos ou listas de discussão, correio eletrônico etc. - e de outros recursos de linguagens digitais de que atualmente dispomos e que podem colaborar significativamente para tornar o processo de educação mais eficiente e mais eficaz. (MASETTO, 2006, p. 152) 
Em função de sua potencialidade, essas tecnologias digitais são cada vez mais utilizadas. Sendo assim, torna-se necessário que profissionais da educação associem seus conhecimentos didático-pedagógicos ao uso desse recurso a fim de fazer com que o uso dessas ferramentas seja favorável e efetivo no que diz respeito à educação. No que se refere, especificamente, à internet, várias são as possibilidades de aplicação no processo de ensino aprendizagem. Uma dessas alternativas é a WQ, que tem se mostrado favorável no que se refere à aplicação de atividades baseadas em pesquisas direcionadas por conteúdos da grande rede. Diante dessa realidade permeada pela utilização intensa das tecnologias digitais, conhecer e explorar metodologias como essa torna-se fator positivo e emergente para a atuação do educador contemporâneo, pois conforme ressalta Lévy (1999) a respeito do potencial do ciberespaço ${ }^{1}$ :

Essa midiateca é povoada, mundial e aumenta constantemente. Ela contém o equivalente a livros, discos, programas de rádio, revistas, jornais, folhetos, curriculum vitae, videogames, espaço de discussão e de encontros, mercados, tudo isso interligado, vivo, fluido. Longe de se uniformizar, a internet abriga a cada ano mais línguas, culturas e variedade. Cabe apenas a nós continuar a alimentar essa diversidade e exercer nossa curiosidade para não deixar dormir, enterradas no fundo do oceano informacional, as pérolas de saber e de prazer - diferentes para cada um de nós - que esse oceano contém. (LÉVY, 1999, p. 9192)

Essa influência do ciberespaço no contexto educativo desencadeia o que Lévy (1996) chama de virtualização do saber, fazendo com que a sociedade encontre-se diante de quatro modos de ser: possível, real, virtual e atual. Tajra (2008, p. 135) faz uma colocação importante acerca do papel do educador desse novo contexto que é “(...) promover o confronto das informações localizadas, verificar a validade delas, procurando sempre estimular o senso crítico dos alunos.”, ou seja, além de reconhecer os benefícios da grande rede é essencial, também, questionar o seu conteúdo, selecionar o que é importante e aplicar de maneira educativa.

Sendo assim, a elaboração desse estudo se deu a partir de uma experiência vivenciada enquanto docente da Disciplina "Ensino Baseado em Web” (EBW) do Curso de Especialização em Tecnologias Educacionais em Laboratórios de Aprendizagem (TLA) de uma faculdade particular da cidade de Uberlândia/MG, destinado a professores da Rede Municipal da mesma localidade. Por acreditar-se na relevância do assunto em questão para o exercício docente, os seguintes tópicos são abordados:

- a utilização da web no contexto educacional;

- a web e a formação docente;

- a metodologia WQ enquanto recurso didático-pedagógico.

O objetivo geral do trabalho realizado foi fornecer alguns subsídios teóricos e práticos, que contribuam com a ação docente apoiada pelo uso das TICs, mais especificamente da internet. Tal propósito de desdobra em três fins específicos:

- conhecer o potencial da web enquanto fonte de informação passível de ser transformada em conhecimento no contexto educacional;

1 Lévy (1999, p.17) em "Cibercultura” conceitua como sendo “(...) o novo meio de comunicação que surge da interconexão mundial dos computadores. O termo específica não apenas a infra-estrutura material da comunicação digital, mas também o universo oceânico de informações que ela abriga, assim como os seres humanos que navegam e alimentam esse universo.” 
- refletir sobre a importância do ensino baseado na web para a formação docente na contemporaneidade;

- utilizar a metodologia WQ enquanto uma das maneiras que contribui com o processo de ensino aprendizagem mediado pelo ciberespaço.

Para tanto, a metodologia utilizada para realização dessa investigação passa pelo estudo teórico, relato de uma experiência docente e análise da vivência relatada a partir do referencial teórico utilizado.

\section{O uso da web no contexto educacional}

O uso da internet como um novo meio de acesso à informação, bem como uma ferramenta que favorece novas formas de aprendizado, comunicação de interação e interatividade tem ocasionado a quebra de barreiras como de espaço, tempo e de acessibilidade. A respeito das influências ocasionadas pela internet no processo de comunicação, Heide e Stilborne (2000) apontam que:

Quando os alunos comunicam-se com as pessoas em lugares estranhos e distantes, eles começaram a atender, apreciar e respeitar as diferenças e similaridades culturais, políticas, ambientais, geográficas e lingüísticas. Sua visão do mundo e de seu lugar no mundo mudam, e o conteúdo do currículo torna-se atual, relevante e integrado a partir de uma perspectiva multidisciplinar e global. (HEIDE e STILBORNE, 2000, p. 24)

Dessa forma, a educação é uma das áreas que precisa se apropriar desse recurso a fim de não contribuir com a permanência de um processo de formação descontextualizado e descomprometido com a realidade do indivíduo. A internet é um dos suportes de proliferação da informação que mais cresce. Tajra (2008, p. 134) ressalta que uma de suas contribuições mais expressivas é "(...) a localização de informações e a comunicação".

Tanto educador, quanto aprendiz, podem desfrutar de tal potencialidade que possibilita o acesso a uma diversidade de fontes de pesquisa, o intercâmbio entre pessoas de diferentes regiões e culturas, compartilhamento e troca de saberes e experiências etc. $\mathrm{O}$ acesso a essa infinidade de recursos e fontes contribui com uma revisão positiva de conceitos e práticas educacionais. Ao educador cabe a responsabilidade de mediar a aprendizagem do indivíduo de maneira envolvente, atrativa e dinâmica, pois a transmissão de conteúdo não cabe mais a esse profissional, mas sim o domínio da informação e de práticas didático-pedagógicas que o permitam se fazer de "ponte" na mutação informação/conhecimento.

Nota-se que com a parceria do docente as tecnologias digitais podem contribuir com um processo cíclico de construção do conhecimento capaz de dar origem a novas fontes de informação que, por sua vez continuarão a alimentar tal curso. Nesse contexto, Alava (2002) faz uma ressalva acerca da relação desse espaço de informação com a leitura que o indivíduo faz do conteúdo disponível nessa grande rede:

A internet não é um espaço educativo construído para o aluno, o estudante, o aprendiz. É um espaço aberto e vivo; portanto, um mundo de risco. Logo, a leitura não é simples, linear, seqüencial. O texto resiste, foge, se esconde, se metamorfoseia. O texto tem de ser capturado, desdobrado, repicado, remontado. A leitura é limite e negociação, está em construção e ação; de fato, a leitura é como 
sempre uma questão de tema e textos. Como qualquer suporte, a net predetermina condutas de leituras, maneiras de fazer, projetos de leituras diferentes e inseridas na própria trama dos sites, dos textos, das páginas. (ALAVA, 2002, p. 205)

Partindo da afirmação acima o autor aponta a existência de quatro tipos de leituras influenciadas pelo ciberespaço: estruturada, ativa, inspirada e de passeio. Esse novo espaço de leitura é oferecido pela internet, mas a maneira que o mesmo é explorado, ou seja, as formas de ação sobre ele são fruto daquele que o utiliza. O que quer dizer que professor e aluno são co-responsáveis pelos hábitos e resultados alcançados com o apoio das novas tecnologias. Nos momentos iniciais, o educador dispõe de uma responsabilidade maior que a do aluno, pois cabe a ele direcionar e aplicar suas práticas a favor do estímulo do uso crítico e educativo por parte do aprendiz. Sendo assim, se faz importante voltar as atenções para o papel de mediador que deve ser assumido pelo docente nesse contexto.

\subsection{O potencial da mediação didático-pedagógica no ciberespaço: algumas possibilidades}

Ao relatar uma experiência no laboratório de informática em "Inclusão digital: tecendo redes afetivas/cognitivas”, Boettcher (2005) aponta que:

No espaço relacional do laboratório, passamos a utilizar a internet como amplo dispositivo para navegar, inventar, mobilizando os alunos a construir novos dispositivos para disparar, para autoconstruir. Abandonou-se, dessa forma, a tradicional postura de dependência para uma crescente autonomização/cooperação, bem no sentido autopoiético como se pretendia, pois ao se apropriarem do disposititvo como algo original, os alunos estavam aptos a construir outros dispositivos, como a homepage, a lista, o e-mail, entre outros. (BOETTCHER, 2005, p. 150)

Esta citação demonstra aquilo que Moran (2006) chama de preocupação com educação de qualidade e apenas com o ensino. Com a educação em foco o educador não se empenha apenas em ensinar ou transmitir, mas em colaborar, estimular, propor condições favoráveis, contextualizadas e animadoras que promovam aspectos como colaboração, produção, crescimento intelectual. Mediar é isso. É atuar em prol da aprendizagem ativa, participativa e colaborativa que ocasiona mudanças positivas no aspecto comportamental, atitudinal e intelectual. A relação professor/aluno deve ser uma relação de parceria e co-participação que visa o exercício de um vínculo dinâmico com os recursos didático-pedagógicos, com o capital humano que o cerca e, principalmente, com o saber. De maneira geral, ser mediador é ser agente de transformação que dialoga, orienta, troca, propõe, colabora, coopera, cria situações problematizadoras, se relaciona com reciprocidade. Acima de qualquer recurso inovador o profissional da educação deve exercer o seu ofício a favor do desenvolvimento dos "Quatro pilares da educação"2 ressaltados por Delors (1999) em que teoria e prática não se separem.

Muitas são as opções encontradas no ciberespaço que servem como alternativas para favorecer um aprendizado mais significativo e envolvente. Diante disso, cabe ao

2 Os quatro pilares foram apresentados no "Relatório para a UNESCO da Comissão Internacional sobre Educação para o Século XXI” por Jaques Delors (1999). São eles: aprender a conhecer, aprender a fazer, aprender a conviver e aprender a ser. Mais informações em: <http://4pilares.net/text-cont/delors-pilares.htm>. Acesso em: 8 out. 2008. 
educador atentar-se à sua finalidade dos recursos sabendo explorá-la e adequá-la à sua proposta educacional de maneira didática, atraente e efetiva. Dessa forma, vale apresentar alguns desses recursos proporcionados pelo uso do computador e da internet como recursos audiovisuais, ambientes virtuais de aprendizagem (AVAs), blogs, compartilhamento de arquivos, ferramentas de comunicação síncrona e assíncrona, hipermídia, hipertextos, redes de comunicação, sites de busca e pesquisa, correios eletrônicos, WQ, wikis etc. Diante dessas inovações, Behrens (2006) traz uma contribuição importante:

Como usuário da rede de informações, o aluno deverá ser iniciado como pesquisador e investigador para resolver problemas concretos que ocorrem no cotidiano de suas vidas. A aprendizagem precisa ser significativa, desafiadora, problematizadora e instigante, a ponto de mobilizar o aluno e o grupo a buscar soluções possíveis para serem discutidas e concretizadas à luz de referenciais teóricos/práticos. (BEHRENS, 2006, p. 77)

Com tantas e inovadas possibilidades tecnológicas a capacitação do educador para lidar com esses recursos torna-se indispensável, pois as tecnologias digitais por si só não se fazem efetivas no que diz respeito à educação se não houver o direcionamento pedagógico que estimule um uso consciente e crítico.

\subsection{A WQ como recurso didático-pedagógico}

A WQ é uma metodologia de pesquisa orientada em recursos do ciberespaço. Idealizada em 1995 pelo professor de tecnologia educacional, o norte-americano, Bernie Dodge da Universidade de San Diego (Califórnia), essa alternativa visa utilizar o conteúdo disponível na internet como fonte de pesquisa em uma proposta pedagógica baseada na investigação.

Até mesmo o Ministério da Educação (MEC, 2008) ${ }^{3}$ aponta a WQ como sendo um dos "(...) recursos, que compõem as tecnologias de construção para Internet e possibilitam a interação com conteúdos educacionais.”. O que vem a ser mais um dos indícios que reforçam a validade da proposta. Seu conteúdo é distribuído em páginas $\mathrm{HTML}^{4}$ divulgadas, ou não, na grande rede. A estrutura proposta por Dodge (1995) possui as seguintes etapas:

- Introdução: parte inicial da WQ que apresenta o tema que será pesquisado. Esta deve despertar o interesse do aprendiz de maneira clara e envolvente.

- Tarefa: nesta deve conter as orientações sobre o trabalho a ser realizado. É importante que o educador faça uso de uma proposta instigante que estimule aspectos como criatividade, colaboração, investigação e o uso de diferentes fontes de pesquisa.

- Processo: indica o caminho que deverá ser seguido para desenvolvimento da tarefa proposta. Informar ao público-alvo as expectativas e a definição de papéis em caso de tarefa coletiva. Ou seja, apresentar um passo a passo minucioso e didático.

- Recursos: estes que também podem ser indicados na etapa anterior, são os subsídios dados ao educando para realização da pesquisa que dará respaldo para cumprir com a atividade proposta. É necessário que essas fontes sejam originadas de

3 Mais informações em: <http://www.webeduc.mec.gov.br/webquest/index.php>. Acesso em: 15 set. 2008.

4 Sigla de Hipertext Markup Language (linguagem de marcação hipertextual). Linguagem baseada em códigos voltados para a construção de páginas para a web. 
conteúdos disponíveis na internet e indicados em forma de links. O educador pode até sugerir outro tipo de fonte como livros, filmes, revistas etc., mas desde que estas sejam indicadas como opções secundárias sem esquecer-se da questão de acessibilidade.

- Avaliação: nesse momento, o aprendiz precisa ter clareza daquilo será apreciado e/ou pontuado ao longo de seu desempenho diante da tarefa proposta. É preciso aterse à coerência do que será avaliado com o nível e com o rigor do trabalho que o aluno desempenhará individualmente ou em grupo.

- Conclusão: parecer final acerca do que foi extraído com o trabalho proposto. Enfatizar os objetivos almejados, a importância do trabalho e estimular a continuidade do estudo são fatores que agregam positividade ao fechamento da WQ.

Na experiência relatada posteriormente propôs-se a inclusão de uma primeira página de “Apresentação", solicitou-se a inclusão dos recursos na página "Processo", incluiu-se também uma página chamada "Destinatários" para informação do públicoalvo e outra chamada "Créditos" para divulgação dos idealizadores e colaboradores da construção, bem como das referências que deram respaldo à criação. A estrutura apresentada por Dodge (1995) dá origem a uma metodologia de pesquisa que pode contribuir expressivamente com o trabalho pedagógico. Para tanto, o docente deve também se preocupar com outros fatores que também influenciam na validade do trabalho. São eles:

- Planejamento: antes de ser estruturada, divulgada e utilizada, a idealização de uma WQ deve partir, primeiramente, de um preparo criterioso, sistemático, coerente e com finalidades educacionais. Dessa maneira, a proposta caminha rumo à efetividade levando em conta as potencialidades e limitações do público-alvo, a efetividade cognitiva e motivacional e o principal: o aprendizado.

- Conteúdo: as passagens textuais contidas em uma WQ devem prezar pela clareza, objetividade e coerência. A proposta de trabalho se faz relevante quando ao abordar uma proposta criativa e inovadora que preze pela busca da aprendizagem significativa por meio do exercício da investigação e da cooperação. Efetividade motivacional e cognitiva devem estar presentes em todas as etapas.

- Estrutura: um dos aspectos atrativos das TICs é o seu potencial hipermidiático, portanto, elaborar uma atividade pedagógica mediada por essas tecnologias carece explorar esse conjunto de qualidades. Fazer uso apenas de informações textuais em uma WQ não é estimulante. O educador precisa, sem excessos, utilizar imagens, efeitos, fundos, apresentações, vídeos etc., ou seja, recursos que explorem os diferentes sentidos e que contribuam com o envolvimento do aprendiz. Os tamanhos e tipos de fontes, assim como as imagens e demais objetos utilizados na confecção das páginas de uma WQ, devem levar sempre em conta o público. Portanto, adequação, coerência, criatividade e didática são imprescindíveis.

Atentando-se a esses princípios, mesmo que iniciante, o educador que se dispõe a fazer uso da WQ ou de qualquer outro recurso que conte com a presença das tecnologias digitais, terá maiores chances de colocar em prática um trabalho efetivo. Nesse sentido, Moran (2008) também complementa:

Uma das formas mais interessantes de desenvolver pesquisa em grupo na Internet é o webquest. Trata-se de uma atividade de aprendizagem que aproveita a imensa riqueza de informações que, dia a dia, cresce na Internet. Resolver uma webquest é um processo de aprendizagem 
atraente, porque envolve pesquisa, leitura, interação, colaboração e criação de um novo produto a partir do material e idéias obtidas. A webquest propicia a socialização da informação: por estar disponível na Internet, pode ser utilizada, compartilhada e até reelaborada por alunos e professores de diferentes partes do mundo. O problema da pesquisa não está na Internet, mas na maior importância que a escola dá ao conteúdo programático do que à pesquisa como eixo fundamental da aprendizagem. (MORAN, 2008)

Essas vantagens, destacadas por vários autores e constatadas por diversos profissionais que já fazem uso da metodologia, reforçam o que Valente e Mattar (2007) falam a respeito da influência dos novos tempos no processo pedagógico. O processo de ensino aprendizagem já não se restringe à sala de aula e o professor, apesar de resistente, precisa adaptar-se ao uso dessas ferramentas tecnológicas tendo em vista uma formação baseada na investigação, na criticidade, na colaboração mútua e na co-autoria. Os benefícios da metodologia WQ, quanto de qualquer outro recurso tecnológico, são resultado da ação docente sobre essas tecnologias. Sendo assim, uma formação docente pautada nas necessidades da sociedade contemporânea deve contemplar a preparação epistemológica e empírica para lidar com esses recursos. A essa discussão o próximo capítulo desse artigo se destina.

\section{O uso da web na formação docente: relato de uma experiência docente}

A capacitação do educador para lidar com o uso das novas tecnologias de maneira pedagógica deve passar por aspectos práticos, teóricos e comportamentais. Isso porque, além de dominar o uso dessas ferramentas de forma coerente com o seu potencial, é importante direcionar esse uso de maneira educativa, assim como entender que a presença dessas tecnologias no dia-a-dia social faz surgir novas maneiras de pensar, agir, relacionar e aprender. A colocação de Tajra (2008) a esse respeito fortalece tal afirmação:

A capacitação do professor deverá envolver uma série de vivências e conceitos, tais como: conhecimentos básicos de informática; conhecimento pedagógico; integração de tecnologia com as propostas pedagógicas; formas de gerenciamento da sala de aula com os novos recursos tecnológicos em relação aos recursos físicos disponíveis e ao "novo" aluno, que passa a incorporar e assumir uma atitude ativa no processo; revisão das teorias de aprendizagem, didática, projetos multi, inter e transdisciplinar. (TAJRA, 2008, p. 106)

A qualificação pode ser entendida como uma responsabilidade pessoal e até institucional. Em função da necessidade de promover qualificação docente frente aos avanços tecnológicos presentes no dia-a-dia social, a Prefeitura Municipal de Uberlândia (MG) lançou, em parceria com o Ministério de Ciência e Tecnologia, o projeto "Digitando o Futuro"5. Atendendo aos objetivos de preparação docente do projeto, a União Educacional Minas Gerais (Uniminas/Faciminas) ofereceu o Curso de Especialização em Tecnologias Educacionais em Laboratórios de Aprendizagem (TLA), cuja gestão foi realizada pelo Núcleo de Educação a Distância (NEAD) da própria instituição. A experiência docente que deu origem a este artigo ocorreu na disciplina "Ensino Baseado em Web” (EBW) que integrou o terceiro módulo do curso passando

5 Mais informações em: VASCONCELOS. Juliene Silva; ROMERO, Maria Helena Cicci. Formação de professores mediada pelas tecnologias: a Rede Municipal de Uberlândia em questão. Disponível em: <ketiuce.hdfree.com.br/TDAE/Artigo_Maria_Helena.pdf>. Acesso em: 20 maio 2010. 
por uma carga-horária de 24h distribuídas de setembro a dezembro de 2008. Desta carga horária, oito horas foram a distância. Cerca de 25\% de carga-horária horária do curso se passou na modalidade EaD por meio de uma dinâmica de estudos realizada no AVA TelEduc. Nesse momento, o curso contava com três turmas com cerca de 30 alunos cada.

Vale ressaltar que a experiência relatada ofereceu condições para tratar de aspectos como a formação docente por meio da Educação a Distância (EaD), pois a estrutura do curso se volta também para uma dinâmica de estudos não presencial em que os professores cursistas puderam realizar suas atividades, ao longo da carga-horária a distância, nos laboratórios da própria instituição ou em espaços que melhor lhes conviessem, além de contarem com o apoio de tutores e professores por meio das ferramentas de comunicação do AVA. A relação do processo de ensino aprendizagem com o apoio das TICs foi outro fator passível de ser observado, visto que todas as disciplinas do curso se voltaram para o saber teórico e prático da ação docente mediada pelas tecnologias digitais. Contudo, o aprofundamento deste artigo se volta para a atuação docente em uma das disciplinas do curso.

Nos momentos a distância explorou-se no AVA ferramentas como fórum de discussão, agenda, correio, portfólio, leituras, material de apoio etc. O conteúdo socializado com os aprendizes visou despertar a reflexão acerca do potencial da web enquanto rica fonte de informação passível de ser transformada em conhecimento desde que bem explorada no sentido didático-pedagógico. Já nos encontros presenciais o trabalho se concentrou na questão prática, ou seja, na construção das páginas da WQ e na sua divulgação na rede. O software utilizado para a edição das páginas foi o FrontPage $^{6}$, já a hospedagem foi realizada por meio do serviço Yahoo Geocities ${ }^{7}$.

Propôs-se que os professores fizessem uso do que já haviam aprendido no decorrer do curso até aquele momento, bem como dos conhecimentos adquiridos na disciplina e das vivências de seu contexto de atuação. Os educandos tiveram acesso a exemplos de WQ, leituras sobre o tema e a tutoriais que, junto com a intervenção da docente e apoio das tutoras, colaborassem com o auxílio ao alunos diante da construção das páginas. O Correio foi a ferramenta de comunicação utilizada pelos aprendizes para esclarecer dúvidas, pedir sugestões e feedback acerca do que já haviam construído. Esta comunicação foi mantida entre os alunos, tutoras e professora da disciplina. Um Fórum de Discussão não avaliativo ficou disponível no decorrer da disciplina em que incentivou-se a troca de percepções, conhecimentos, sugestões, descobertas e demais aspectos relevantes para o aprendizado teórico e prático do que foi proposto. A maior parte dos alunos participou com intervenções que refletiam envolvimento, satisfação e interesse no aprendizado e na colaboração.

A discussão incentivou que os participantes socializassem descobertas, fizessem indicações e refletissem em conjunto sobre o uso das novas tecnologias, principalmente, da metodologia WQ em seu espaço de atuação. Procurou-se enfatizar a importância da parceria entre tecnologia e educação e a necessidade de planejamento, qualidade estrutural e efetividade pedagógica da metodologia. Dessa forma, em todos os contatos presenciais e virtuais, esse destaque se fez presente. Dois dificultadores foram apontados pelos professores ao longo da disciplina: o escasso tempo para dedicação às tarefas em tempo extra, e a pouca fluência tecnológica inicial para lidar com as novas ferramentas que lhes eram apresentadas.

6 Programa da Microsoft destinado à criação e ao gerenciamento de páginas web.

7 Serviço que já foi oferecido pelo site Yahoo que possibilitava a hospedagem gratuita, bem como o gerenciamento de home pages. 
Ao final das criações, solicitou-se que os alunos divulgassem no Mural do AVA os endereços de suas páginas, e incentivou-se o uso do que foi aprendido na disciplina para futuras criações. Assim as criações puderam ser difundidas e apreciadas pelos colegas de turma, bem como levadas para aplicação em suas escolas. As avaliações permearam produções individuais e em duplas, a fim de incentivar os alunos a se aproximarem mais de alguns recursos que para eles, em um primeiro momento, despertou certa frustração e medo pela carente fluência tecnológica inicial. Os alunos também tiveram que se auto-avaliar e avaliar a produção de outro colega com base nos critérios que foram apresentados como necessários para contribuir com a efetividade da metodologia.

As avaliações focaram processo e resultado, objetivando aliar qualidade estética e efetividade pedagógica, pois muitas produções se deslumbravam com o uso de imagens, efeitos, sons etc., mas pecavam no foco da aprendizagem. Enquanto que outras, apresentavam rica proposta didático-pedagógica, mas não a adaptava de maneira eficiente à estrutura da WQ. Ao final da disciplina percebeu-se que os professores cursistas já haviam desenvolvido um olhar mais criterioso acerca das suas próprias produções e de produções alheias e, o mais importante, mostraram que o aprendizado foi válido em seu campo de atuação, pois passaram a socializar resultados obtidos em seus espaços de trabalho com o uso da WQ por meio de trabalhos de conclusão de módulo e de conclusão de curso.

\section{Considerações finais}

A procura dos professores pela formação para lidar com o uso das tecnologias a favor do processo de ensino aprendizagem é algo que reforça a influência das novas tecnologias nos mais diferentes contextos, o que torna necessária a capacitação para lidar com tal realidade. Isso porque, a efetividade da mediação didático-pedagógica apoiada pelas tecnologias digitais, está diretamente ligada à competência do educador em utilizá-las a favor dos objetivos de aprendizagem. Nesse contexto, tanto educador quanto aprendiz, devem ater-se à necessidade de assumirem papéis de parceiros e autores de um processo de ensino aprendizagem que rompe as barreiras de espaço e tempo, mas que carece de fatores indispensáveis como: domínio do uso das tecnologias digitais, disciplina, determinação, comprometimento, maturidade, autonomia, proatividade, colaboração etc.

Sendo a educação uma necessidade influenciada, em grande parte, por profissionais que detêm o ofício de educar, estes precisam se manter constantemente preparados e abertos para atenderem às necessidades educacionais que mudam conforme o contexto social do educando muda. As TICs são recursos importantes devido ao seu potencial de estimular envolvimento, criatividade, inovação e colaboração, porém por traz do seu uso deve haver uma postura pedagógica e consciente dos seus perigos. O respeito pela privacidade, pela imagem alheia, para com a veracidade do que se divulga e pensar nas conseqüências causadas pelo uso que se faz do recurso, são critérios que precisam ser questionados por todos os usuários.

Dessa forma, recai sobre o educador a responsabilidade de pensar e agir como um profissional que forma opiniões, influencia pensamentos, estimula comportamentos, enfim, que se faz participante no processo de formação formal e informal de um cidadão. Sendo assim, entende-se que discurso e práticas de educador devem estar voltados para aspectos como contexto, realidade, necessidades e interesses do aprendiz. As tecnologias digitais fazem parte desse contexto, além de demonstrarem potencial que 
vai além da questão de modernização. Portanto, preparar o docente no sentido técnico e epistemológico para atuar nessas circunstâncias, mais que um diferencial, é uma necessidade. Caso o contrário ocorra, contribui-se para uma sociedade mais excludente, seletiva, acrítica, desenformada, despreparada e manipulada pelos avanços tecnológicos, quando deve ser o oposto.

\section{Referências}

ALAVA, Séraphin (Org.). Ciberespaço e formações abertas: rumo a novas práticas educacionais? Tradução Fátima Murad. Porto Alegre: Artmed, 2002. 224 p.

BOETTCHER, Dulci. A internet como dispositivo potencializador didático. In: SCHLÜNZEN, Elisa Tomoe Moriya; JUNIOR, Klaus Schlünzen; PELLANDA, Nize Maria Campos (Org.). Inclusão digital: tecendo redes afetivas/cognitivas. Rio de Janeiro: DP\&A, 2005. p. 145-161.

HEIDE, Ann; STILBORN, Linda. Guia do professor para a internet: completo e fácil. Tradução de Edson Furmankiewz. 2. ed. Porto Alegre: Artes Médicas, 2000. 337 p.

LÉVY, Pierre. Cibercultura. 2. ed. 6. reimp. Tradução de Carlos Irineu Costa. São Paulo: 34, 1999. 264 p. Título original: Cyberculture.

O que é o virtual. 7. reimp. Tradução de Paulo Neves. São Paulo: 34. 1996. 160 p. Título original: Qu’est-ce que Le virtuel?

MORAN, José Manuel. As possibilidades das redes de aprendizagem. Disponível em: <http://www.eca.usp.br/prof/moran/redes_aprendizagem.htm>. Acesso em: 3 nov. 2008.

MORAN, José Manuel; MASETTO, Marcos T.; BEHRENS, Marilda Aparecida. Novas tecnologias e mediação pedagógica. 12 ed. Campinas: Papirus, 2006. 173 p.

TAJRA, Sanmya Feitosa. Informática na educação: novas ferramentas pedagógicas para o professor na atualidade. 8. ed. rev e amp. São Paulo: Érica: 2008. 198 p.

VALENTE, Carlos; MATTAR, João. Second Life e Web 2.0 na Educação: o potencial revolucionário das novas tecnologias. São Paulo: Novatec, 2007. 280 p. 